\title{
Cohesion and Coherence in Written Texts of Students of Faculty of Education
}

\author{
Abdulkerim Karadeniz $^{1}$ \\ ${ }^{1}$ Department of Turkish Education, Faculty of Education, Ahi Evran University, Kirsehir, Turkey \\ Correspondence: Abdulkerim Karadeniz, Department of Turkish Education, Faculty of Education, Ahi Evran University, \\ Kirsehir, Turkey.
}

Received: November 20, 2016

Accepted: January 3, $2017 \quad$ Online Published: January 6, 2017

doi:10.11114/jets.v5i2.1998

URL: http://dx.doi.org/10.11114/jets.v5i2.1998

\begin{abstract}
The purpose of this study is to determine the relationship between Faculty of Education students' levels of using cohesive devices and their skills in creating a consistent text. The document review technique, which is one of the qualitative research methods, was employed in the study. The "Cohesive Devices Evaluation Scale" was employed in determining the coherency factors in the students' texts, and the "Paragraph Consistency Evaluation Scale" was employed in the evaluation of the consistency of the texts. The study was carried out at the Faculty of Education, Ahi Evran University in the 2014-2015 academic year. The students' skills in using cohesive devices, elliptical narrative and conjunctive components are varies significantly depending on the department in which they are receiving their education. It is observed that there is a highly significant relationship between the length of the text and coherence and consistency. Again, it is observed that there is a significant relationship in a positive direction between consistency and coherence. A significant relationship at a low level between the students' skills in creating a consistent text and references, elliptical narrative and substitution of the cohesive devices is also seen.
\end{abstract}

Keywords: cohesive devices, text linguistics, writing education, writing quality

\section{Introduction}

Text linguistics and reading and writing training are closely related. Reading texts, comprehension and the production of texts are the basic activities in native and foreign language education. While other disciplines are primarily interested in the content of the texts, information provided by the texts, the delivery style of the text and the impact of the text, text linguistics are interested in the rules influencing the production of the text itself, production of the texts and their communicative functions (Senoz, 2005).

In reading education, finding the message delivered by the author based on text structure, separation of text structures, identification of the elements of cohesion and finding the elements of coherence provides a better understanding and interpretation of the text. According to Diliduzgun (2013), reading exercises should not be limited to the reading-understanding questions; how the text is written should be explained by analyzing it in terms of purpose, viewpoint, plan, integrity and consistency as well.

In writing education, how the elements of cohesion and coherence affect the writing quality and how the students' ability to use the tools of cohesion can be improved based on the qualities of a good text are the important issues. Students must know where to start, what to do at each stage and what is expected of them when writing texts (Diliduzgun, 2013). Writing is the process of putting the information structured in the mind on paper. For this, it is necessary for students to understand what they hear and read well and structure it in their minds (Akdal and Sahin, 2014). Here, text linguistics arises as a new method to be used by students in designing both what they write and read in such a way that their texts present a structural integrity and that they can systematize it in their minds.

The aim of writing education is to provide students with the ability to express their emotions and ideas properly. Applied studies on writing education usually involve grammatical errors in student essays, ambiguities in expression

*This study was presented at the IIIrd International Eurasian Educational Research Congress, Mugla, 31 May-3 June 2016. 
and problems in structural qualities and rarely focus on intra-textual connections, transitions, the formation of text elements, topic flow within the text and the text structures that form the basis of the essay. The researchers who have taken this into account (Bae, 2001; Can, 2012; Coskun, 2005; Karatay, 2010; Ramadan, 2003; Said, 1988; Witte and Faigley, 1981) have focused on studying the structural elements that form the text in the light of text linguistics and investigated the correlation between students' use of "tools of cohesion" in their writing and in how they form a coherent text.

Every text includes a meaning and a message, either verbally or visually. To understand this message requires analyzing the text. There are different theories and methods for analyzing different kinds of texts (Kuzu, 2016). One of these methods is text linguistics. This is a new approach that evaluates a text based on its structural and semantic integrity and understands the basic elements of the text based on this evaluation. It reveals the connection and the relationship between the semantic groups within the text (Aytas, 2008). Text linguistics tries to reveal the text's structure by evaluating the text in terms of what are probably the two most important criteria: cohesion and coherence.

Texts are structures comprising words, prefixes and suffixes and sentences. These elements come together and complete each other, forming meaningful phrases. Therefore, revealing the connection between these prefixes and suffixes, words and phrases is important in order to make a sound interpretation of the text. Revealing the connection is what we call cohesion. Cohesion in a text is to use other elements to explain or interpret an element within the text and to make explanations based on these elements.

Gutwinski (1976) used the term cohesion for relationships existing between the sentences and clauses within the text. According to him, these relations occurring on a grammatical layer point to certain grammatical and lexical qualities that reflect semiotic discourse structure.

Tools of cohesion can be defined as the semantic relationships between an element and another element that plays an important role in the comprehension of the first element within the text. Two elements that are semantically connected can be within the same text or one can be from outside of the text (Witte and Faigley, 1981). While reference, conjunction and lexical cohesion are common in written expressions, ellipsis and substitution are used in oral expressions (de Beaugrande and Dressier, 1981; Witte and Faigley, 1981). According to Halliday and Hasan (1976), cohesion is a concept that is referred to by the semantic relationship within a text and arises when the interpretation of an element in a discourse is dependent on another element.

In the literature, there are different opinions on the classification of the tools of cohesion. Halliday and Hasan (1976), Gunay (2001), Onursal (2003), Uzun (1995) and Balci (2009) classify the tools of cohesion differently. In this study, the classification of the tools of cohesion is based on "Cohesion in English" by Halliday and Hasan and the tools are evaluated under the headings reference, ellipsis, substitution, conjunction and lexical cohesion.

Another element that text linguistics focuses on and accepts as a criterion of a text is coherence. It is what is sought-after in a text rather than cohesion, and if it is not found the text is considered inadequate and incomplete (Aytas, 2008). In a well-prepared text, besides the formal tools of cohesion, semantic coherence should be found. Coherence of the text comprises the comprehensive realization of what is discussed in the text, the text having succeeding statements which are supportive of those preceding, and the text not contradicting itself.

While coherence is defined in the early studies of text linguistics as the link that contains all kinds of grammatical and semantic relationships between the sentences that form a text, over time the grammatical relationships have been evaluated under the concept of cohesion and coherence has instead been regarded as the semantic and logical linkage within the text (Toklu, 2003). According to Aksan (1999), cohesion defines the grammatical links between the sentences that form the text while coherence indicates the semantic and logical links between those sentences. According to Witte and Faigley (1981), cohesion defines the mechanisms that bring the text together while coherence defines the semantic relationships that enable a text to be understood and utilized.

The students' written texts are evaluated based on formal properties, such as writing, punctuation and grammar, whereas they should be evaluated based on the properties of a quality text, such as the logical coherence and integrity of the written subject, appropriate transitions between paragraphs, the main idea being supported by the assisting ideas and the final part of the text being conclusive and effective. Therefore, under these circumstances, studies to improve the writing skills of students to ensure appropriate transitions between paragraphs, the integration of the main idea with assisting ideas and the overall consistency of the text are underestimated. Many students who have completed their secondary education have difficulties expressing themselves in writing (Can, 2012; Karatay, 2010).

\subsection{Objective of the Study}

The aim of this study is to investigate the relationship between the Faculty of Education students' ability to use the tools of cohesion and to form a coherent text. In the light of this aim, the questions raised are as follows: 
1. Does the ability of students to use tools of cohesion in their writing differ depending on their department of study?

2. Does the ability of students to form a coherent text differ depending on their department of study?

3. Is there a relationship between the length of the text and cohesion and coherence?

4. Is there a relationship between tools of cohesion (reference, ellipsis, substitution, conjunction and lexical cohesion) and coherence of the text?

\section{Method}

\subsection{Research Design}

As one of the qualitative data collection techniques, the document review technique was used in this study, which examines the relationship between the level of using cohesion tools and their skills of forming a coherent text in students of a Faculty of Education. Document review examination includes the analysis of written materials containing information about the phenomenon or phenomena that are aimed to be investigated (Yildirim and Simsek, 2013).

\subsection{Study Group}

The study was carried out with 126 pre-service teachers chosen with stratified sampling from among approximately 320 $1^{\text {st }}$ grade students studying at the Faculty of Education, Ahi Evran University, during the fall semester of the 2014-2015 academic year. Stratified sampling is a sampling method that ensures that the sub-groups in the sampling universe are determined and they are represented in the sample in the same proportion as in the universe (Buyukozturk et al., 2015). When the individuals in the universe are randomly selected, their characteristic rates may be the same or different in the sample and stratification secures representation in this respect (Creswell, 2014). Stratified sampling was performed in order to ensure that students were equally represented in terms of the variables of their department and grade level. 23 students from the Department of Turkish Language, 21 students from the Department of Classroom Teaching, 21 students from the Department of Social Sciences Teaching, 18 students from Science, 23 from Information Technologies Teaching, and 20 students from Primary School Mathematics Teaching participated in the study. 49 of the study group were male and 77 were female.

\subsection{Data Collection Tools}

The written studies of the students were evaluated in terms of the concepts of coherence and consistency that have been accepted as the criteria of text linguistics. Halliday and Hasan's (1976) coherence taxonomy was used in this study. The "Coherence Tools Evaluation Scale" developed by Coskun (2005) was used in the determination of the coherence tools in the texts. With this scale, the aim was to find the average usage of the coherence tools in the the students' writings and express them using numerical data. The "Paragraph Consistency Evaluation Scale" developed by Can (2012) was used in the evaluation of the texts in terms of consistency. The formula of a = Range / Number of the Groups to be Formed was used in the determination of the group value interval of the scale (Tasdemir, 2003). Accordingly, the score interval was determined at a level between 1 and 4 as follows: "insufficient" (1.00-1.75), "medium" (1.76-2.50), "good" (2.51-3.25), "very good" (3.26-4.00)."

The "Harmony between independent observers" method was used in order to determine the reliability of the measurement tools used in the study. Harmony between independent observers is a reliability criterion that is applied when more than one observer tries to measure the same thing independently from one another (Karasar, 2005). Accordingly, thirty randomly selected written papers were evaluated by the researcher, one Turkish teaching and two Turkish language and literature teaching experts. Then the relations between these values were determined using the Pearson Product Moment Correlation Coefficient Analysis. The Pearson correlation coefficient, which shows the rate of consistency between those analysing the students' writings, was performed as follows: $r=.81$ in the scores of the use of coherence tools; $r=.76$ in consistency scores. That the Pearson correlation coefficient is between .70 and .89 shows that there is a high degree of relationship and that it is above .90 shows that the relationship is very high (Kalayci, 2009: 116).

\subsection{Data Analysis}

First, the fitness of the data for normal distribution was examined to determine the statistical method to be used in the study. The Kolmogorov-Smirnov normal distribution test was performed as the number of the data was higher than 50 in order to test the fitness of the data for normal distribution (Wright, 2006: 94). As a result of the normal distribution test, it was determined that the level of significance was higher than 0.05 , and it was concluded that the data show normal distribution considering the kurtosis, skewness coefficients and histogram graph (Kalayci, 2009: 6-10). Thus, single way variance analysis (ANOVA) was used in order to determine whether the level of using coherence tools and consistent text formation skills of the students varied by the department in which they were studying. In addition to this, the Pearson Product Moment Correlation Coefficient (r) was calculated in the determination of the relations between the 
length of the text and coherence and consistency, and the relations between the consistency of the text and coherence tools (reference, elliptical expression, substitution, connection elements and word coherence). The SPSS 15.0 program was used in the analysis of the data, and a significance level of 0.05 was sought in the interpretation of the data.

\section{Findings}

In this section, the ability of students to use tools of cohesion and form a coherent text is interpreted in tabular form by using statistical methodology appropriate to the aims of this study. Table 1 shows the statistical values assessed by the analyses performed to investigate the students' ability to use the tools of cohesion depending on their department of study.

Table 1. Mean, Standard Deviation and Single Factor ANOVA results on the ability of students to use the tools of cohesion depending on their department of study

\begin{tabular}{|c|c|c|c|c|c|c|c|c|}
\hline $\begin{array}{l}\text { Cohesion } \\
\text { Measures }\end{array}$ & Department & $\mathrm{n}$ & $X$ & SS & Sd & $\mathrm{F}$ & $\mathrm{P}$ & $\begin{array}{l}\text { Significant } \\
\text { Difference }\end{array}$ \\
\hline \multirow{6}{*}{ Reference } & Turkish Lang. & 23 & 15.60 & 6.562 & \multirow{6}{*}{$5 / 120$} & \multirow{6}{*}{2.184} & \multirow{6}{*}{.060} & \multirow{7}{*}{ 年 } \\
\hline & Primary School & 21 & 15.28 & 6.907 & & & & \\
\hline & Social Sciences & 21 & 13.19 & 5.767 & & & & \\
\hline & Sciences Teach. & 18 & 12.27 & 5.549 & & & & \\
\hline & Computer Teach. & 23 & 10.95 & 5.489 & & & & \\
\hline & Mathematics & 20 & 12.10 & 4.678 & & & & \\
\hline \multirow{6}{*}{ Ellipsis } & Turkish Lang. & 23 & 20.17 & 6.161 & \multirow{6}{*}{$5 / 120$} & \multirow{6}{*}{3.452} & \multirow{6}{*}{.006} & \\
\hline & Primary School & 21 & 17.85 & 5.322 & & & & \multirow{5}{*}{$\begin{array}{l}\text { A-E } \\
\text { A-F }\end{array}$} \\
\hline & Social Sciences & 21 & 17.00 & 7.204 & & & & \\
\hline & Sciences Teach. & 18 & 16.50 & 4.668 & & & & \\
\hline & Computer Teach. & 23 & 14.43 & 4.550 & & & & \\
\hline & Mathematics & 20 & 14.20 & 5.454 & & & & \\
\hline \multirow{6}{*}{ Substitution } & Turkish Lang. & 23 & .47 & .790 & \multirow{6}{*}{$5 / 120$} & \multirow{6}{*}{1.976} & \multirow{6}{*}{.087} & \multirow{6}{*}{ - } \\
\hline & Primary School & 21 & .33 & .577 & & & & \\
\hline & Social Sciences & 21 & .14 & .358 & & & & \\
\hline & Sciences Teach. & 18 & .22 & .548 & & & & \\
\hline & Computer Teach. & 23 & .08 & .288 & & & & \\
\hline & Mathematics & 20 & .10 & .307 & & & & \\
\hline \multirow{6}{*}{ Conjunctions } & Turkish Lang. & 23 & 20.39 & 8.606 & \multirow{6}{*}{$5 / 120$} & \multirow{6}{*}{3.732} & \multirow{6}{*}{.004} & \multirow{6}{*}{ B-E } \\
\hline & Primary School & 21 & 21.14 & 6.010 & & & & \\
\hline & Social Sciences & 21 & 17.90 & 5.769 & & & & \\
\hline & Sciences Teach. & 18 & 17.44 & 5.962 & & & & \\
\hline & Computer Teach. & 23 & 14.21 & 5.116 & & & & \\
\hline & Mathematics & 20 & 15.90 & 5.990 & & & & \\
\hline \multirow{6}{*}{$\begin{array}{l}\text { Lexical } \\
\text { Cohesion }\end{array}$} & Turkish Lang. & 23 & 51.91 & 15.931 & \multirow{6}{*}{$5 / 120$} & \multirow{6}{*}{.267} & \multirow{6}{*}{.931} & \multirow{6}{*}{ - } \\
\hline & Primary School & 21 & 51.00 & 12.393 & & & & \\
\hline & Social Sciences & 21 & 49.61 & 12.757 & & & & \\
\hline & Sciences Teach. & 18 & 53.61 & 10.971 & & & & \\
\hline & Computer Teach. & 23 & 50.73 & 18.454 & & & & \\
\hline & Mathematics & 20 & 49.00 & 10.867 & & & & \\
\hline
\end{tabular}

A= Turkish Lang, B= Primary School, C= Social Sciences, D= Sciences Teach., E= Computer Teach., F= Mathematics

Table 1 shows that the ability of the students to use ellipsis and conjunctions as tools of cohesion has a significant difference $(p<0.05)$ depending on their department of study. There is no significant difference $(p>0.05)$ in reference, substitution and lexical cohesion depending on the students' department of study. The Scheffe test was conducted to identify the difference between the groups based on the department of study and the results showed that there is a significant difference in the average use of ellipsis between the students in Turkish Teaching and Computer Technologies and Mathematics Teaching departments. The arithmetic mean of the group suggests that the average use of ellipsis is higher in students in the Turkish Teaching department compared to students from other departments.

The results on the use of conjunctions show that the average use by the students of Classroom Teaching and Computer Technologies Teaching is significantly different $(\mathrm{p}<0.05)$. This difference is in favour of the Classroom Teaching students. Table 2 shows the statistical values assessed by the analyses performed to investigate the students' ability to form a coherent text depending on their department of study. 
Table 2. Mean, Standard Deviation and Single Factor ANOVA results on the ability of students to form a coherent text depending on their department of study

\begin{tabular}{lllllllll}
\hline & Department & $\mathrm{N}$ & $\bar{X}$ & $\mathrm{SS}$ & $\mathrm{Sd}$ & $\mathrm{F}$ & $\mathrm{P}$ & $\begin{array}{c}\text { Significant } \\
\text { Difference }\end{array}$ \\
\hline \multirow{5}{*}{ Coherence } & Turkish Language & 23 & 3.96 & .512 & & & & \\
& Primary School & 21 & 3.90 & .392 & & & & A-D \\
& Social Sciences & 21 & 3.59 & .538 & \multirow{2}{*}{$5 / 120$} & \multirow{2}{*}{4,861} & \multirow{2}{*}{000} & A-E \\
& Sciences Teach. & 18 & 3.43 & .618 & & & & B-E \\
& Computer Teach. & 23 & 3.39 & .428 & & & & \\
& Mathematics & 20 & 3.67 & .466 & & &
\end{tabular}

$\mathrm{A}=$ Turkish Lang, $\mathrm{B}=$ Primary School, $\mathrm{C}=$ Social Sciences, $\mathrm{D}=$ Sciences Teach., E= Computer Teach., F= Mathematics

According to Table 2, while Turkish Teaching students received the highest score in the coherence evaluation scale on a scale of 5 (3.96), students of the Computer Technologies Teaching department received the lowest score (3.39). The Scheffe test was conducted to identify the difference between the groups based on the department of study and a significant difference was found between Turkish Teaching, Computer Technologies and Mathematics Teaching departments, and Classroom Teaching and Mathematics Teaching departments $(\mathrm{p}<0.05)$. Table 3 shows the statistical values assessed in the analyses performed to investigate the relationship between the length of the text and the students' ability to form a coherent text and use the tools of cohesion.

Table 3. Mean, Standard Deviation and Single Factor ANOVA results on the relationship between the length of the text and the students' ability to form a coherent text and use the tools of cohesion

\begin{tabular}{|c|c|c|c|c|}
\hline & & Text Length & Coherence & Cohesion \\
\hline \multirow{2}{*}{ Text Length } & $\mathrm{r}$ & 1 & $.475^{* *}$ & $.740 * *$ \\
\hline & $\mathrm{p}$ & & .000 & .000 \\
\hline \multirow{2}{*}{ Coherence } & $\mathrm{r}$ & $.475 * *$ & 1 & $.426 * *$ \\
\hline & $\mathrm{p}$ & .000 & & .000 \\
\hline \multirow{2}{*}{ Cohesion } & $\mathrm{r}$ & $.740 * *$ & $.426 * *$ & 1 \\
\hline & $\mathrm{p}$ & .000 & .000 & \\
\hline
\end{tabular}

$\mathrm{n}=126, *$ Correlation is significant at the level of $0.05 . * *$ Correlation is significant at the level of 0.01 .

Table 3 shows the highly significant relationship between the coherence $(r=.475, p<.05)$ and cohesion $(r=.740, p<.05)$ and the length of the text. It can be seen that there is a positive and significant relationship between coherence and cohesion $(r=.426, p<.05)$. Table 4 shows the statistical values assessed in the analyses performed to investigate the relationship between the ability to form a coherent text and the tools of cohesion.

Table 4. The table of correlation between the students' ability to form coherent texts and use the tools of cohesion

\begin{tabular}{lccccccc}
\hline & & Coherence & Reference & Ellipsis & Substitution & Conjunctions & $\begin{array}{c}\text { Lexical } \\
\text { Cohesion }\end{array}$ \\
\hline Coherence & $\mathrm{r}$ & 1 & $.208^{*}$ & $.302^{*}$ & $.224^{*}$ & $.448^{* *}$ & $.347^{* *}$ \\
& $\mathrm{p}$ & & .020 & .001 & .012 & .000 & .000 \\
Reference & $\mathrm{r}$ & $.208^{*}$ & 1 & $.316^{* *}$ & $.236^{* *}$ & $.561^{* *}$ & .130 \\
& $\mathrm{p}$ & .020 & & .000 & .008 & .000 & .147 \\
Ellipsis & $\mathrm{r}$ & $.302^{*}$ & $.316^{* *}$ & 1 & .167 & $.491^{* *}$ & .131 \\
& $\mathrm{p}$ & .001 & .000 & & .062 & .000 & .145 \\
Substitution & $\mathrm{r}$ & $.224^{*}$ & $.236^{* *}$ & .167 & $.04 * *$ &. .021 \\
Conjunctions & $\mathrm{p}$ & .012 & .008 & .062 & & .001 & .812 \\
Lexical & $\mathrm{p}$ & $.448^{* *}$ & $.561^{* *}$ & $.491 * *$ & $.304 * *$ & .001 & $.261^{* *}$ \\
Cohesion & $\mathrm{p}$ & .000 & .000 & .000 & .001 & .003 \\
\hline
\end{tabular}

$\mathrm{n}=126,{ }^{*}$ Correlation is significant at the level of $0.05 . * *$ Correlation is significant at the level of 0.01 .

In Table 4 it can be seen that there is a low-level and significant relationship between the students' ability to form coherent texts and to use tools of cohesion such as reference $(r=.208, p<.05)$, ellipsis $(r=.302, p<.05)$ and substitution $(\mathrm{r}=.224, \mathrm{p}<.05)$. The correlation between the ability to form a coherent text and conjunctions $(\mathrm{r}=.448, \mathrm{p}<.05)$ and lexical cohesion $(\mathrm{r}=.347, \mathrm{p}<.05)$ is moderate and significant.

\section{Discussion and Conclusion}

In this study, carried out to determine the relationship between Faculty of Education students' skills in using cohesive devices and their skills in creating consistent texts, the following results were found and are discussed below.

When the students' skills in using cohesive devices are examined depending on the department in which they were receiving their education, it is observed that there is a significant difference in the elliptical narrative and conjunctive 
elements $(\mathrm{p}<0.05)$. In reference, substitution and word coherency, there is not a significant statistical differentiation depending on the department in which students were receiving their education $(\mathrm{p}>0.05)$. On examining the literature, as a department-based comparison had not been carried out in the studies previously performed, a comparison of the results of these studies could not be carried out.

When the students' skills in creating consistent texts are examined in respect to the department in which they were being educated, it is observed that, out of a total of 4 points in the Consistency Evaluation Scale, students in the Department of Turkish Language got the highest score (3.16) and students in the Department of Computer Technologies Teaching got the lowest score (2.71). This may result from the fact that Turkish Language Education students take more writing and reading education courses and these students are more eager with regard to reading and writing compared to students in other departments.

It is observed there is a highly significant relationship between the length of the text and consistency $(r=.475, \mathrm{p}<.05)$ and coherence $(\mathrm{r}=.740, \mathrm{p}<.05)$. Coskun (2005) and Bae (2001) also achieved similar results in their studies. This situation may be connected to the text organisation skills of the students writing longer compositions; along with this, the students writing longer texts have a more positive attitude towards writing.

It is observed that there is a significant relationship in a positive direction between consistency and coherence $(\mathrm{r}=.426$, p <.05). Coskun (2005), Karatay (2010) and Yang and Sun (2012) found that there is a high-level relationship between the use of cohesive devices and skills in creating a consistent text in their studies. It can be said that this result may have originated from the use of cohesive devices such as word coherence and conjunction elements which can affect the writing quality directly. This is because these two cohesive devices are indicators of the students' writing skills and the quality of their writing. The frequency of the use of conjunction elements arises as an indicator of the text quality. In the same manner, the frequent use of word coherence in the text may be an indicator of the students' reading and writing skills. The more students express their emotions and ideas with various words in the text, the more the text they write becomes rich in terms of expressions.

It was concluded that there is a significant relationship at a low level between the students' skills in creating consistent texts and reference $(r=.208, \mathrm{p}<.05)$, elliptical narrative $(r=.302, \mathrm{p}<.05)$, and substitution $(r=.224, \mathrm{p}<.05)$ from among the cohesive devices. It is observed that the relationship between the skill of being able to create consistent texts and the conjuctive elements $(r=.448, \mathrm{p}<.05)$ and word coherency $(\mathrm{r}=.347, \mathrm{p}<.05)$ is significant at a mid-level. These results demonstrate similarity with the studies carried out by Bae (2001), Coskun (2005), Lui and Brane (2005), Karatay (2010) and Yang and Sun (2012).

In reference to the results above, it can be said that there is a relationship between the consistency and length of text and the use of cohesive devices; thus, reading and writing exercises carried out with regard to the students' skill in using cohesive devices will also affect the students' skill in creating consistent texts.

\section{Recommendations}

In reference to the results of the study, the following recommendations can be put forward to develop students' writing skills:

It is necessary to include exercises towards developing the students' skills in creating texts with semantic integrity, rather than correcting the formal mistakes in students' written narratives in writing education.

Teachers should have students do applied exercises about how they should use conjunctive elements in a sentence, between sentences and between paragraphs.

Doing exercises to prevent the students from repeating the same word very frequently or to promote the use of synonyms or the reference elements instead of that word may be beneficial. In this way it will be possible to educate individuals with a rich vocabulary.

It may be beneficial to determine the structure of the texts taught during the classes or demonstrate the relations between these structures to help the students sustain consistency in the texts they write.

\section{References}

Akdal, D., \& Sahin, A. (2014). The effects of inter-textual reading approach on the development of creative writing skills, Eurasian Journal of Educational Research, 54, 171-186. http://dx.doi.org/10.14689/ejer.2014.54.10

Aytas, G. (2008). Poem analyses in the light of modern developments. Ankara: Akcag.

Bae, J. (2001). Cohesion and coherence in children's written English: Immersion and English-only classes. Issues in Applied Linguistics, 12(1), 51-88. Retrieved from http://languagetesting.info/articles/store/ialreprintbae.pdf

Balci, H. A. (2009). A Cognitive General Overview on the Text Linguistics. Ankara: Bizbize. 
Buyukozturk, S. (2008). Data analysis handbook for social sciences. Ankara: Pegem A Publishing.

Buyukozturk, S., Cakmak, E. K., Akgun, O. E., Karadeniz, S., \& Demirel, F. (2015). Scientific research methods. Ankara: Pegem Akademi.

Can, R. (2012). Cohesion and coherent at the level of paragraph in the compositions of secondary school students. (Unpublished doctoral dissertation). Gazi University, Ankara.

Cohen, J. (1988). Statistical power analysis for the behavioral sciences. Hillsdate, NJ: Lawrence Erlbaum Associates.

Coskun, E. (2005). Cohesion, coherence and text elements in narrative texts of primary school students. (Unpublished doctoral dissertation). Gazi University, Ankara.

Creswell, J. W. (2014). Research design qualitative, quantitative, and mixed methods approaches. Ankara: Egiten Kitap.

De Beaugrande, R., \& Dressier, W. (1981). Introduction to text linguistics. London: Longman.

Diliduzgun, S. (2013). The effect of process writing activities on the writing skills of prospective Turkish teachers. Egitim Arastirmalari-Eurasion Journal of Educational Research, 52, 189-210. Retrieved from http://www.ejer.com.tr/0DOWNLOAD/pdfler/tr/11-30506_Dilduzgun_final\%20_189-210_.pdf

Gunay, V. D. (2001). Text information. Istanbul: Multilingual Publishing.

Halliday, M. A. K., \& Hasan, R. (1976). Cohesion in English. New York: Longman Group UK Limited.

Huck, S. W. (2008). Reading statistics and research. $5^{\text {th }}$ Edition. New York: Addison Wesley Longman.

Kalayci, S. (2009). SPSS applied multi-variable statistics techniques. Ankara: Asil Publishing.

Karasar, N. (2005). Research method. Ankara: Nobel Publishing.

Karatay, H. (2010). The correlation between application level of cohesion and writting a coherent text. Mustafa Kemal University Journal of Social Sciences Institute, 7(13), 373-385. Retrieved from http://www.mku.edu.tr/files/25_dosya_1337108236.pdf

Kuzu, S. T. (2016). The impact of a semiotic analysis theory-based writing activity on students' writing skills. Eurasian Journal of Educational Research, 63, 37-54. http://dx.doi.org/ 10.14689/ejer.2016.63.3

Lui, M., \& Brane, G. (2005). Cohesive features in argumentative writing produced by Chinese undergraduates. Elsevier, 33, 623-636. Retrieved from http://www.sciencedirect.com/science/article/pii/S0346251X05000692

Onursal, I. (2003). Coherence and consistency in Turkish texts. A. E. Kiran, E. Korkut, S. Agildere (Eds.), Today Linguistics Studies. Istanbul: Multilingual Publishing.

Ramadan, S. M. S. (2003). Cohesion in written works of the twelfth grade students of literary and scientific streams at state secondory schools in Jordan. (Unpublished doctoral dissertation). Gazi University, Ankara.

Said, H. A. (1988). The cohesive role of reference, subsititution and ellipsis in two genres of modern literary Arabic. (Unpublished doctoral dissertation). Texas A\&M University, Texas. Retrieved from https://www.researchgate.net/publication/34845911

Senoz, C. A. (2005). Text linguistics and Turkish. Istanbul: Multilingual.

Uzun, L. S. (1995). Notices on some text linguistics aspects in Turkish. The 4th Linguistics Symposium (17-18 May 1990), Istanbul: Bogazici University Publishing.

Witte, S. P., \& Faigley, L. (1981). Coherence, cohesion and writing quality. College Composition and Communication, 32(2), 189-204. Retrieved from https://www.la.utexas.edu/users/faigley/work/coherence.pdf

Yang, W., \& Sun, Y. (2012). The use of cohesive devices in argumentative writing by Chinese EFL learners at different proficiency levels. Linguistics and Education, 23, 31-48. Retrieved from http://www.sciencedirect.com/science/article/pii/S0898589811000842

Yildirim, A., \& Simsek, H. (2013). Qualitative research methods in social sciences. Ankara: Seckin Publishing.

\section{Copyrights}

Copyright for this article is retained by the author(s), with first publication rights granted to the journal.

This is an open-access article distributed under the terms and conditions of the Creative Commons Attribution license which permits unrestricted use, distribution, and reproduction in any medium, provided the original work is properly cited. 